\title{
Irbesartan, an angiotensin receptor blocker, exhibits metabolic, anti-inflammatory and antioxidative effects in patients with high-risk hypertension
}

\author{
Isao Taguchi ${ }^{1}$, Shigeru Toyoda ${ }^{1}$, Kazuhiko Takano $^{1}$, Takuo Arikawa ${ }^{1}$, Migaku Kikuchi $^{1}$, Mikie Ogawa $^{1}$, \\ Shichiro Abe ${ }^{1}$, Koichi Node ${ }^{2}$ and Teruo Inoue ${ }^{1}$
}

Irbesartan, an angiotensin II receptor blocker (ARB), acts as a selective PPAR- $\gamma$ (peroxisome proliferator-activated receptor- $\gamma$ ) modulator, and thus may have anti-inflammatory and antioxidative effects, as well as beneficial effects on glucose and lipid metabolism. We enrolled 118 high-risk hypertensive outpatients, defined as those with the presence of at least one complication such as coronary artery disease, cerebrovascular disease or diabetes, and who were receiving any ARB except for irbesartan (67 \pm 10 years, $80 \%$ male subjects). After a 4-week control period, all ARBs were switched to an equivalent dose of irbesartan. We evaluated changes in lipid parameters, inflammatory markers and derivatives of reactive oxygen metabolites (dROMs) as an oxidative stress index. After 12 weeks of irbesartan, there were significant decreases in triglycerides ( $138 \pm 73$ versus $\left.123 \pm 65 \mathrm{mg} \mathrm{dl}^{-1}, P<0.05\right)$, high-sensitivity C-reactive protein (hs-CRP) $\left(2.80 \pm 0.53\right.$ versus $2.66 \pm 0.50, \log \left(\mathrm{ng} \mathrm{ml}^{-1}\right)$, $P<0.05)$ and d-ROMs $(338 \pm 74$ versus $305 \pm 62$ U.CARR, $P<0.001$ ). There were significant increases in high-density lipoprotein cholesterol ( $50 \pm 13$ versus $52 \pm 14 \mathrm{mg} \mathrm{dl}^{-1}, P<0.01$ ) and adiponectin $\left(9.4 \pm 6.2\right.$ versus $16.6 \pm 13.4 \mathrm{ng} \mathrm{ml}^{-1}$, $P<0.05)$. There were no significant changes in systolic and diastolic blood pressure. The change in d-ROMs from baseline to 12 weeks was positively correlated with the change in hs-CRP $(R=0.34, P<0.01)$. Irbesartan appears to exert beneficial effects on oxidative stress, inflammation, lipid metabolism and metabolic syndrome, indicating that it may be useful in highrisk hypertensive patients.

Hypertension Research (2013) 36, 608-613; doi:10.1038/hr.2013.3; published online 21 February 2013

Keywords: angiotensin receptor blocker; inflammation; irbesartan; lipid metabolism; oxidative stress

\section{INTRODUCTION}

Angiotensin II type 1 receptor blockers (ARBs), which act by selectively blocking the binding of angiotensin II to the angiotensin II type 1 receptor, are widely used in the treatment of hypertension. ${ }^{1-3}$ These agents have benefits that go beyond blood pressure control, and there is emerging evidence that ARBs have cardiovascular, cerebral and renal protective effects via inhibition of renin-angiotensin activation at the tissue level, an autocrine/paracrine effect. ${ }^{4,5}$ In addition to direct end-organ protection, ARBs have been suggested to improve abnormalities in glucose and lipid metabolism, and metabolic syndrome. ${ }^{6}$ ARBs have also been suggested to ameliorate inflammation and oxidative stress, and this may lead to cardiovascular protection because both inflammation and oxidative stress have seminal roles in the pathophysiology of cardiovascular events.

The family of transcription factors termed peroxisome proliferatoractivated receptors (PPARs) has recently been the focus of much interest because of their possible role in the regulation of inflammation, as well as glucose and lipid metabolism. Among various ARBs, irbesartan acts as a partial agonist of PPAR- $\gamma$, which is similar to telmisartan. ${ }^{7,8}$ In addition to blocking angiotensin II type 1 receptors, telmisartan has been shown to improve insulin resistance and hypertriglyceridemia by its PPAR- $\gamma$ agonist, thereby improving the metabolic syndrome. ${ }^{6,7,9,10}$ However, the metabolic effects of irbesartan have not been well investigated. In addition, an experimental study has shown that irbesartan induces cellular expression and activation of antioxidant enzymes, ${ }^{11}$ suggesting that irbesartan may be a potential antioxidant. However, the antioxidative effects of irbesartan have not been established, especially in the clinical setting.

We conducted the I-Mets (irbesartan's metabolic, anti-inflammatory and antioxidative properties) study to investigate the clinical effects of irbesartan on metabolic status, inflammation and oxidative stress, and the correlation between these parameters in high-risk hypertensive patients.

\section{METHODS}

Study design

For the I-Mets study, we recruited 132 outpatients with high-risk hypertension, defined as those with the presence of at least one complication such as 
coronary artery disease, cerebrovascular disease or diabetes. All patients were receiving an ARB, but not irbesartan, for over 3 months and had stable blood pressure. We provided an additional 4-week control period to select patients whose blood pressure was well controlled, with systolic blood pressure $<135$ and diastolic blood pressure $<85 \mathrm{~mm} \mathrm{Hg}$. After the control period, all patients were switched to irbesartan with a dose that corresponded to that of the former ARB. We assessed blood pressure and heart rate, and performed blood sampling for measurement of lipids, glucose, and inflammatory and oxidative stress markers at the following three time points: at the beginning of the observation period, just prior to starting irbesartan and after 12 weeks of irbesartan. During the 12 weeks of irbesartan treatment, the dose of irbesartan was not changed. Each time blood tests were performed, fasting venous blood was taken from the antecubital vein. Sampled blood was used first for routine blood tests that included lipid profiles and glucose metabolism. The remaining blood was immediately centrifuged at $1500 \times g$ for $15 \mathrm{~min}$ at room temperature, and used for measurement of inflammatory and oxidative stress markers. The serum was frozen and stored at $-80^{\circ} \mathrm{C}$ until analyzed. The study protocol was approved by the local medical ethics committee, and informed consent was obtained from each patient.

\section{Measurement of blood pressure and heart rate}

Measurement of blood pressure was made in duplicate at each clinic visit $24 \pm 4 \mathrm{~h}$ after the intake of the study medication. Duplicate measurements were separated by an interval of at least $5 \mathrm{~min}$ after the patients had rested in the seated position for at least $5 \mathrm{~min}$. Office blood pressures were measured to the nearest $2 \mathrm{~mm} \mathrm{Hg}$ in the same arm at each visit using a mercury sphygmomanometer with an appropriately sized cuff. Heart rate was measured by pulse palpation for $30 \mathrm{~s}$ immediately after the blood pressure measurement.

\section{Lipid profiles and glucose metabolism parameters}

For determination of lipid profiles and glucose metabolism parameters, the levels of serum total cholesterol, triglyceride, high-density lipoprotein (HDL)cholesterol, fasting blood glucose and glycohemoglobin Alc were measured. Total cholesterol and triglyceride levels were determined using enzymatic methods. HDL-cholesterol was measured using the precipitation method. Fasting blood glucose was assayed using the glucose oxidase method. HbAlc was measured by high-performance liquid chromatography and expressed as the value of the National Glycohemoglobin Standardization Program. Lowdensity lipoprotein (LDL)-cholesterol was calculated using the Friedewald formula: (LDL-cholesterol $=$ total cholesterol $-\mathrm{HDL}$-cholesterol - triglyceride/ 5). Patients with a triglyceride level over $400 \mathrm{mg} \mathrm{dl}^{-1}$ were excluded from the subjects for whom the LDL-cholesterol was calculated.

\section{Measurement of inflammatory markers}

In this study, high-sensitivity $\mathrm{C}$ reactive protein (hs-CRP) levels were measured by particle-enhanced technology on a Behring BN II nephelometer (Dade Behring Inc, Newark, DE, USA), using monoclonal anti-CRP antibodies and a calibrator that was traceable to World Health Organization (WHO) reference material. ${ }^{12}$ We also measured matrix metalloproteinase (MMP)-9, myeloperoxidase and adiponectin using the Luminex micro-beads array system, which was designed as a multiplex assay capable of simultaneously quantitating multiple biomarkers. The assay was conducted according to the manufacturer's instructions (Luminex Corp., Austin, TX, USA), using a commercially available kit (BioSource International, Inc, Camarillo, CA, USA). The reliability, reproducibility and sensitivity of this technology have been established, and are comparable to conventional measurement methods. ${ }^{13,14}$

\section{Derivatives of reactive oxygen metabolites (d-ROMs) evaluation}

Oxidative stress is defined as an imbalance between the production of reactive oxygen metabolites (ROMs), (that is, metabolites of reactive oxygen specimen), and the removal of reactive oxygen specimen by a variety of endogenous and exogenous antioxidants. In this study, we assessed oxidative stress using a simple method for the evaluation of ROMs, the d-ROMs test, which has been developed recently. ${ }^{15-17}$ It is based on the determination of hydroperoxides in blood. Free radical activity is evaluated by measuring hydroperoxide serum levels by the d-ROMs test (Diacron, Grosseto, Italy). The d-ROMs test is a photometric method based on the radical reaction of Fenton, further elaborated in the biochemical field by Haber and Weiss. ${ }^{18}$ The test measures the amount of hydroperoxides in serum. Hydroperoxides are strictly correlated with the amount of ROMs and free radicals from which hydroperoxides are derived. In the d-ROMs test, the hydroperoxides in the serum sample react with a chromogenic substrate that produces a colored derivative. The reaction temperature is $37^{\circ} \mathrm{C}$. The colored complex is detected and quantified by a photometer (FREE, Diacron) at a wavelength of $505 \mathrm{~nm}$. The results of the d-ROMs test are expressed in arbitrary units, the so-called Caratelli Units (U.CARR), where 1 U.CARR corresponds to $0.08 \mathrm{mg}$ per $100 \mathrm{ml} \mathrm{H}_{2} \mathrm{O}_{2}$.

\section{Data analysis}

The data were collected at the following three time points: the beginning of the control period as baseline, just prior to irbesartan administration and 12 weeks after irbesartan administration. Normality of the distribution of variables was assessed using a Kolmogorov-Smirnov test with Lilliefors' correlation. As the distribution of the hs-CRP values was non-parametric, it was transformed into logarithmic values. Serial changes in the values were assessed by repeated measures analysis of variance. Correlations were assessed using simple linear regression. Values are expressed as the mean \pm s.d. A $P$-value $<0.05$ was considered statistically significant.

\section{RESULTS}

Of a total of 132 patients recruited, 14 were eliminated from the study because of discontinuation of irbesartan, treatment at another hospital or other reasons. The data were analyzed for the remaining 118 patients (94 men and 24 women, mean age: 64 years). In these 118 patients, previously prescribed ARBs were candesartan in 33 (28\%), losartan in $13(11 \%)$, valsartan in $38(33 \%)$, olmesartan in 11 (9\%) and telmisartan in 22 patients (19\%). Combined antihypertensive drugs were calcium channel blockers in 70 (59\%), $\beta$-blockers in $15(13 \%), \alpha$-blockers in $16(14 \%)$ and thiazide diuretics in $12(10 \%)$. Antidiabetic drugs and statins were prescribed in 31 (26\%) and 105 patients $(89 \%)$, respectively (Table 1). None of these drugs were discontinued during the study period. The dose of irbesartan was $50 \mathrm{mg}$ per day in 18 (15\%), $100 \mathrm{mg}$ per day in 53 (45\%) and $200 \mathrm{mg}$ per day in 47 patients (40\%).

Serial changes in the measured parameters are shown in Table 2. There were no significant changes in systolic blood pressure (123 \pm 12

\section{Table 1 Baseline characteristics in 118 patients}

$\begin{array}{lc}\text { Age; years } & 64 \pm 26 \\ \text { Male gender; } n \text { (\%) } & 94(80) \\ \text { Ischemic heart disease; } n \text { (\%) } & 94(80) \\ \text { Cerebrovascular disease; } n \text { (\%) } & 4(3) \\ \text { Diabetes; } n \text { (\%) } & 55(47) \\ & \\ \text { Baseline angiotensin receptor blockers } & \\ \text { Candesartan; } n(\%) & 33(28) \\ \text { Losartan; } n(\%) & 13(11) \\ \text { Valsartan; } n(\%) & 38(33) \\ \text { Olmesartan; } n(\%) & 11(9) \\ \text { Telmisartan; } n(\%) & 22(19) \\ & \\ \text { Combined drugs } & \\ \text { Ca blockers; } n(\%) & \\ \beta \text {-blockers; } n(\%) & 70(59) \\ \alpha \text {-blockers; } n(\%) & 15(13) \\ \text { Thiazide; } n(\%) & 16(14) \\ \text { Antidiabetic drugs; } n(\%) & 12(10) \\ \text { Statins; } n(\%) & 31(26) \\ & 105(89)\end{array}$


Table 2 Changes in parameters after irbesartan treatment

\begin{tabular}{|c|c|c|c|}
\hline & Baseline & $\begin{array}{l}\text { Prior to irbesartan } \\
\text { administration }\end{array}$ & $\begin{array}{c}12 \text { weeks after } \\
\text { irbesartan } \\
\text { administration }\end{array}$ \\
\hline $\begin{array}{l}\text { Systolic BP; mm Hg } \\
(n=118)\end{array}$ & $123 \pm 12$ & $123 \pm 12$ & $122 \pm 12$ \\
\hline $\begin{array}{l}\text { Diastolic BP; } \mathrm{mm} \mathrm{Hg} \\
(n=118)\end{array}$ & $71 \pm 8$ & $70 \pm 8$ & $70 \pm 7$ \\
\hline Heart rate; $/ \min (n=118)$ & $72 \pm 11$ & $73 \pm 12$ & $72 \pm 12$ \\
\hline $\begin{array}{l}\text { Total cholesterol; } \mathrm{mg} \mathrm{dl}^{-1} \\
(n=118)\end{array}$ & $151 \pm 15$ & $152 \pm 26$ & $149 \pm 26$ \\
\hline $\begin{array}{l}\text { LDL-cholesterol; } \mathrm{mg} \mathrm{dl}^{-1} \\
(n=118)\end{array}$ & $74 \pm 20$ & $74 \pm 21$ & $71 \pm 18$ \\
\hline $\begin{array}{l}\text { HDL-cholesterol; } \mathrm{mg} \mathrm{dl}^{-1} \\
(n=118)\end{array}$ & $49 \pm 10$ & $50 \pm 13$ & $52 \pm 14^{* *}$ \\
\hline $\begin{array}{l}\text { Triglyceride; } \mathrm{mg} \mathrm{dl}^{-1} \\
(n=118)\end{array}$ & $140 \pm 80$ & $138 \pm 73$ & $123 \pm 65^{*}$ \\
\hline $\begin{array}{l}\text { Fasting blood glucose; } \\
\mathrm{mgdl}^{-1}(n=118)\end{array}$ & $108 \pm 27$ & $109 \pm 32$ & $106 \pm 34$ \\
\hline $\mathrm{HbA1c} ; \%(n=104)$ & $6.1 \pm 0.9$ & $6.1 \pm 0.9$ & $6.2 \pm 1.0$ \\
\hline $\begin{array}{l}\text { hs-CRP; log }\left(\mathrm{ng} \mathrm{ml}^{-1}\right) \\
(n=79)\end{array}$ & $2.83 \pm 0.53$ & $2.80 \pm 0.54$ & $2.66 \pm 0.50^{*}$ \\
\hline MMP-9; mg ml-1 $(n=77)$ & $1.12 \pm 0.74$ & $1.03 \pm 0.86$ & $0.62 \pm 0.59$ \\
\hline $\begin{array}{l}\text { Myeloperoxidase; } I \mathrm{U} \mathrm{ml}^{-1} \\
(n=77)\end{array}$ & $1.55 \pm 0.71$ & $1.50 \pm 0.70$ & $0.51 \pm 0.43$ \\
\hline $\begin{array}{l}\text { Adiponectin; } \mu \mathrm{g} \mathrm{ml}^{-1} \\
(n=77)\end{array}$ & $9.2 \pm 7.3$ & $9.4 \pm 6.2$ & $16.6 \pm 13.4^{* * *}$ \\
\hline d-ROMs; U.CARR $(n=90)$ & $344 \pm 80$ & $338 \pm 74$ & $305 \pm 62^{* * *}$ \\
\hline
\end{tabular}

Abbreviations: BP, blood pressure; d-ROMs, derivative of reactive oxygen metabolites; HbAlc, hemoglobin Alc; HDL, high density lipoprotein; hs-CRP, high-sensitivity C-reactive protein LDL, low-density lipoprotein; MMP-9, matrix metalloproteinase-9.

$* P<0.05, * * P<0.01, * * * P<0.001$ versus prior to irbesartan administration.

versus $123 \pm 12 \mathrm{~mm} \mathrm{Hg}$ ) or diastolic blood pressure (71 \pm 8 versus $70 \pm 8 \mathrm{~mm} \mathrm{Hg}$ ) during the 4 -week control period. The blood pressure also did not change after 12 weeks of irbesartan (systolic: $123 \pm 12$ versus $122 \pm 12$, diastolic: $70 \pm 8$ versus $70 \pm 7 \mathrm{~mm} \mathrm{Hg}$ ). Heart rate also did not change significantly over the three time points (Table 2). The levels of LDL-cholesterol, fasting blood glucose and HbAlc did not change significantly during the observation period, including control and irbesartan treatment. Although the levels of HDLcholesterol $\left(49 \pm 10\right.$ versus $\left.50 \pm 13 \mathrm{mg} \mathrm{dl}^{-1}\right)$ and triglyceride $\left(140 \pm 80\right.$ versus $\left.138 \pm 73 \mathrm{mg} \mathrm{dl}^{-1}\right)$ did not change during the control period, the HDL-cholesterol level increased $(50 \pm 13$ versus $\left.52 \pm 14 \mathrm{mg} \mathrm{dl}^{-1}, \quad P<0.01\right)$ and the triglyceride level decreased $\left(138 \pm 73\right.$ versus $\left.123 \pm 66 \mathrm{mg} \mathrm{dl}^{-1}, P<0.05\right)$ significantly after 12 weeks of irbesartan. The level of hs-CRP (2.83 \pm 0.53 versus $\left.2.80 \pm 0.54 \log \left(\mathrm{ng} \mathrm{ml}^{-1}\right)\right)$ and adiponectin (9.2 \pm 7.3 versus $9.4 \pm 6.2 \mu \mathrm{g} \mathrm{ml}^{-1}$ ) did not change during the control period. However, the hs-CRP level decreased (2.80 \pm 0.54 versus $\left.2.66 \pm 0.50 \log \left(\mathrm{ng} \mathrm{ml}^{-1}\right), P<0.05\right)$ and the adiponectin level increased $\left(9.4 \pm 6.2\right.$ versus $\left.16.6 \pm 13.4 \mu \mathrm{g} \mathrm{ml}^{-1}, P<0.001\right)$ significantly after irbesartan administration. The levels of MMP-9 (1.12 \pm 0.74 versus $\left.1.03 \pm 0.86 \mathrm{mg} \mathrm{ml}^{-1}\right)$ and myeloperoxidase $(1.51 \pm 0.71$ versus $1.50 \pm 0.70 \mathrm{IU} \mathrm{ml}^{-1}$ ) did not change significantly during the control period. The levels showed a decreasing trend after irbesartan administration (MMP-9: $1.03 \pm 0.86$ versus $0.62 \pm 0.59 \mathrm{mg} \mathrm{ml}^{-1}, P=0.062$, myeloperoxidase: $1.50 \pm 0.70$ versus $\left.0.51 \pm 0.43 \mathrm{IU} \mathrm{ml}^{-1}, P=0.057\right)$. The d-ROM levels did not change ( $344 \pm 80$ versus $338 \pm 74$ U.CARR)

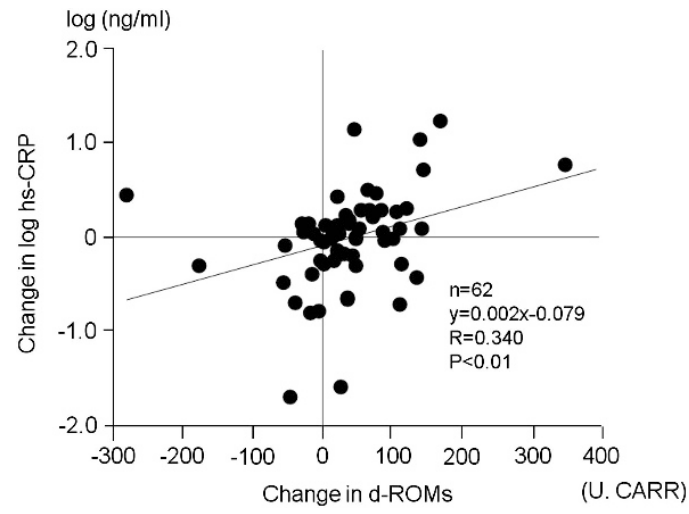

Figure 1 Positive correlation between the change in d-ROMs after irbesartan administration (the value prior to irbesartan administration minus that after 12 weeks of irbesartan administration) and that of hs-CRP (logtransformed).

during the control period, but decreased (338 \pm 74 versus $306 \pm 62$ U.CARR, $P<0.001)$ significantly after irbesartan administration.

The change in d-ROMs after irbesartan administration (the value prior to irbesartan administration minus that after 12 weeks of administration) correlated positively with the change in hs-CRP $(R=0.340, P<0.01)$ (Figure 1), whereas it did not correlate with changes in the levels of HDL-cholesterol $(R=-0.09)$, triglyceride $(R=0.12)$ or adiponectin $(R=-0.13)$.

Figure 2 shows the changes in d-ROMs after irbesartan administration in the subgroups of patients who were treated with irbesartan doses of 50, 100 and $200 \mathrm{mg}$ per day. The d-ROMs decreased equally in the groups treated with $50 \mathrm{mg}$ per day $(337 \pm 82$ versus $308 \pm 64$ U.CARR, $P<0.01), 100 \mathrm{mg}$ per day $(340 \pm 76$ versus $304 \pm 56$ U.CARR, $P<0.001)$ and $200 \mathrm{mg}$ per day $(336 \pm 80$ versus $307 \pm 74$ U.CARR, $P<0.001)$.

When the subgroup of patients that had previously received telmisartan were compared with the patients who received other ARBs, the triglyceride level was lower (132 \pm 70 versus $\left.143 \pm 83 \mathrm{mg} \mathrm{dl}^{-1}, P<0.05\right)$ and the adiponectin level was higher (14.6 \pm 7.3 versus $6.4 \pm 5.2 \mu \mathrm{g} \mathrm{ml}^{-1}, P<0.01$ ), but the levels of HDLcholesterol $\left(52 \pm 20\right.$ versus $\left.49 \pm 12 \mathrm{mg} \mathrm{dl}^{-1}\right)$, hs-CRP $(2.68 \pm 0.49$ versus $2.89 \pm 0.58 \log \left(\mathrm{ng} \mathrm{ml}^{-1}\right)$ ) and d-ROMs (337 \pm 60 versus $340 \pm 84$ U.CARR) were similar just prior to switching to irbesartan. After 12 weeks of irbesartan in the group that had previously received telmisartan, the levels of triglyceride $\left(128 \pm 76 \mathrm{mg} \mathrm{dl}^{-1}\right)$, HDLcholesterol $\left(52 \pm 16 \mathrm{mg} \mathrm{dl}^{-1}\right)$, adiponectin $\left(17.4 . \pm 5.8 \mu \mathrm{g} \mathrm{ml}^{-1}\right)$ and hs-CRP $\left(2.64 \pm 0.52 \log \left(\mathrm{ng} \mathrm{ml}^{-1}\right)\right)$ were not significantly different compared with the levels just prior to irbesartan treatment. However, d-ROMs decreased significantly after 12 weeks of irbesartan treatment (340 \pm 84 versus $298 \pm 74$ U.CARR, $P<0.05$ ) (Figure 3).

\section{DISCUSSION}

In the present study, we observed that 12 weeks' irbesartan administration improved lipid metabolism in high-risk hypertensive patients, as demonstrated by an increase in HDL-cholesterol levels and a decrease in triglyceride levels, as well as an increase in adiponectin levels. In addition, we observed that irbesartan treatment also improved oxidative stress, as well as inflammation, as demonstrated by a reduction in d-ROM and hs-CRP levels. The change in d-ROMs correlated with that in hs-CRP, but did not correlate with changes in HDL-cholesterol, triglyceride and adiponectin. The 


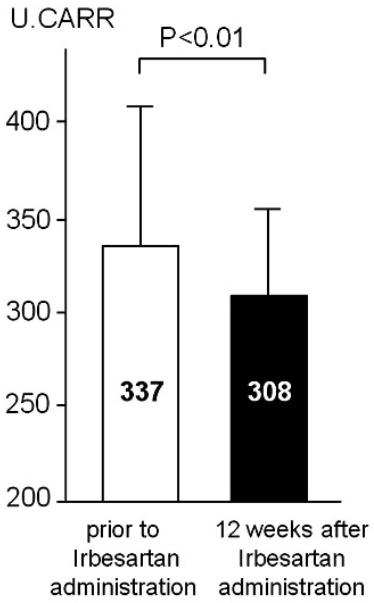

$50 \mathrm{mg} /$ day $(\mathrm{n}=14)$

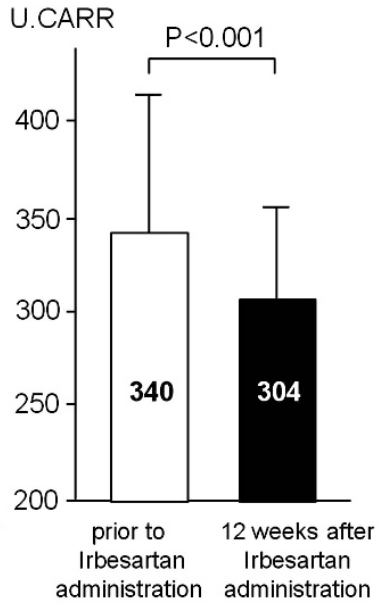

$100 \mathrm{mg} /$ day $(\mathrm{n}=44)$

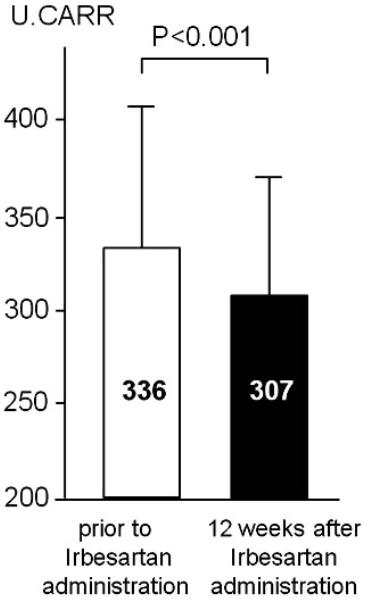

$200 \mathrm{mg} /$ day $(\mathrm{n}=32)$

Figure 2 Changes in d-ROMs after irbesartan administration in subgroups of patients stratified based on the irbesartan dose (50, 100 and 200 mg per day). The d-ROMs decreased to a similar extent in each subgroup.
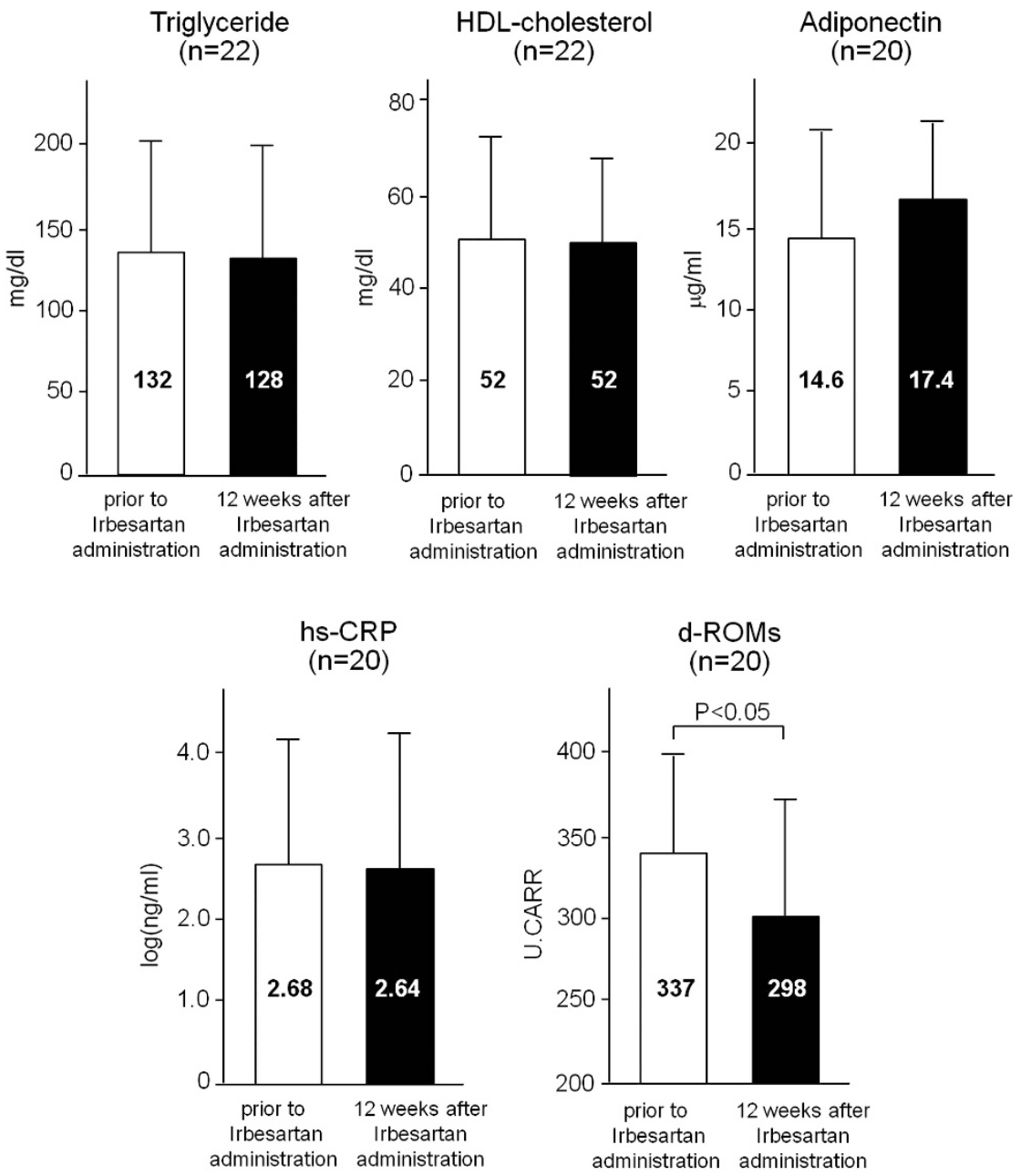

Figure 3 Changes in triglyceride, HDL-cholesterol, adiponectin, hs-CRP and d-ROMs after switching to irbesartan in the subgroup of patients who received telmisartan before irbesartan. The levels of triglyceride, HDL-cholesterol, adiponectin and hs-CRP did not change, but d-ROMs decreased significantly.

improvements in lipid metabolism, oxidative stress and inflammation were observed when patients switched from other ARBs to irbesartan, but were not associated with changes in blood pressure. These results suggest that the metabolic, anti-inflammatory and antioxidative effects of irbesartan might be stronger than those of other ARBs, and might be independent of its blood-pressure-lowering effects. 
Irbesartan is an established ARB that is approved worldwide for the treatment of hypertension. Its renoprotective effects in hypertensive patients with diabetic nephropathy have been established in large clinical trials. ${ }^{19,20}$ However, the cardiovascular protective effects of irbesartan are controversial. Whereas the Irbesartan in Diabetes Nephropathy Trial (IDNT) ${ }^{20}$ demonstrated that irbesartan reduced the incidence of heart failure episodes in hypertensive patients with diabetic nephropathy, compared with placebo or amlodipine, the Irbesartan in Heart Failure With Preserved Ejection Fraction (I-PRESERVE) trial $^{21}$ showed that irbesartan did not yield cardiovascular benefits compared with placebo in heart failure patients with a preserved ejection fraction. The recent Atrial Fibrillation Clopidogrel Trial with Irbesartan for Prevention of Vascular Event (ACTIVE-I) trial ${ }^{22}$ reported that irbesartan was not associated with a reduction in a composite endpoint of cardiovascular death, heart attack or stroke compared with the placebo groups, but there was a $14 \%$ reduction in the risk of hospitalization as a result of heart failure in the irbesartan group.

There is substantial clinical evidence that ARBs exert a beneficial effect on glucose and lipid metabolism, and improve the metabolic syndrome. In patients with metabolic syndrome, insulin resistance results in increased triglyceride levels and decreased HDL-cholesterol levels. ${ }^{23}$ As angiotensin II impairs insulin signaling, ARBs increase insulin sensitivity, ${ }^{24}$ and thus, may decrease triglyceride levels and increase HDL-cholesterol levels. Furthermore, it is well known that ARBs increase plasma adiponectin levels as a class effect. ${ }^{25,26}$ In addition, certain ARBs, such as irbesartan and telmisartan, have been identified as partial PPAR- $\gamma$ agonists. ${ }^{6,27,28}$ It is well known that PPAR- $\gamma$ has an important role in regulating glucose and lipid metabolism, and that ligands for PPAR- $\gamma$ can improve insulin sensitivity, resulting in reduced triglyceride levels and increased HDL-cholesterol levels. ${ }^{29-31}$ PPAR- $\gamma$ agonism also increases plasma adiponectin levels. ${ }^{32}$ Therefore, ARBs that activate PPAR- $\gamma$ should improve insulin resistance, reduce triglyceride levels, and increase HDL-cholesterol and adiponectin levels more than ARBs that lackPPAR- $\gamma$ agonist activity.

Angiotensin II is involved in key events of the inflammatory process and oxidative stress in cardiovascular disease. Angiotensin II initiates the inflammatory cascade of NADH/NADPH oxidase, reactive oxygen specimen and an inflammatory nuclear transcription factor, nuclear factor- $\kappa \mathrm{B} .{ }^{33}$ In addition, adiponectin is also closely related to the inflammatory process, and thus ARBs, especially PPAR$\gamma$-activating ARBs, may inhibit the inflammatory reaction. ${ }^{34}$ Irbesartan has been shown to increase the intracellular expression and activation of antioxidant enzymes such as $\mathrm{Cu} / \mathrm{Zn} / \mathrm{Mn}$ superoxide dismutase, catalase and glutathion peroxidase in skin fibroblasts of early diabetic angiopathy patients, ${ }^{11}$ suggesting that irbesartan acts as an antioxidant. In this study, we observed antioxidative effects of irbesartan as demonstrated by decreased levels of d-ROMs, a novel global oxidative stress marker that is easy to measure. Our study is the first to show decreased oxidative stress after the treatment of hypertensive patients with irbesartan. In addition, we found that the reduction of d-ROM levels after irbesartan administration was positively correlated with the reduction in hs-CRP levels but not with changes in HDL-cholesterol, triglyceride or adiponectin levels. These results suggest that the antioxidative effect of irbesartan might be associated with its anti-inflammatory properties, but independent of its metabolic effects. The usual starting dosage of irbesartan is $100 \mathrm{mg}$ per day, and in Japan that dose can be titrated up to $200 \mathrm{mg}$ per day if necessary, although the usual dosage is $150-300 \mathrm{mg}$ per day in the Western countries. In our study, the lower dose of $50 \mathrm{mg}$ per day was administered to $18 \%$ of patients. The decrease in d-ROM levels after switching to irbesartan was similar in the subgroups that were treated with 50, 100 and $200 \mathrm{mg}$ per day, suggesting that the antioxidative effect of irbesartan is dose-independent.

Telmisartan is another representative ARB that activates PPAR- $\gamma$, and there are several studies that show that telmisartan improves glucose and lipid metabolism, insulin resistance and metabolic syndrome. ${ }^{35}$ However, there are few reports comparing irbesartan with telmisartan, and our study provides the first evidence that irbesartan increases adiponectin levels. In our subgroup analysis, where the patients who received telmisartan prior to the initiation of irbesartan were compared with those who received other ARBs, the triglyceride levels were lower and the adiponectin levels were higher just prior to switching to irbesartan. In the telmisartan subgroup, the levels of HDL-cholesterol, triglyceride and adiponectin did not change after 12 weeks of irbesartan treatment. These results suggest that the metabolic effects of irbesartan might be equivalent to those of telmisartan. However, d-ROMs still decreased after irbesartan in those patients who received telmisartan prior to irbesartan. This finding suggests that irbesartan has a stronger antioxidative effect than telmisartan.

In our study, we simultaneously assessed MMP-9 and myeloperoxidase as inflammatory markers. MMP-9, a proteolytic enzyme released from inflammatory cells, is considered to have a pathogenic role in the development of atherosclerotic plaques. Myeloperoxidase, which produces reactive oxygen specimen during the respiratory burst of activated neutrophils, is thought to have a role in inflammatory as well as oxidative processes in cardiovascular disease. In our study, these inflammatory markers did not show statistically significant changes but a decreasing trend after irbesartan treatment. These results might also indicate the anti-inflammatory and antioxidative effects of irbesartan.

\section{Study limitations}

This study has several potential limitations. First, this study was prospective, but there was only a single treatment arm to evaluate the effects of irbesartan. We could not directly compare the effects of irbesartan with those of other ARBs or with a control group as the patients were not randomized. However, we provided a 4 -week control period to select patients whose blood pressure was well controlled by other ARBs. Consequently, all of the measured parameters, including the values of triglyceride, HDL-cholesterol, adiponectin, hs-CRP and d-ROMs, did not change during the control period. Therefore, we believe the changes in these biomarkers after switching to irbesartan provide evidence for the cardiovascular protective effects of irbesartan. Second, although our data suggest that irbesartan has metabolic, anti-inflammatory and antioxidative effects, we were not able to determine the specific mechanisms responsible for these effects (that is, angiotensin receptor blockade, PPAR- $\gamma$ agonism, both or other unknown mechanisms). Additional information from future experimental studies, as well as clinical studies, is needed to address these mechanisms. Finally, we do not know whether the metabolic, anti-inflammatory and antioxidative effects of irbesartan, as demonstrated in this study, could reduce cardiovascular mortality and morbidity in patients with high-risk hypertension. Large-scale randomized clinical trials with long-term outcomes are required to address this issue.

\section{CONCLUSIONS}

Irbesartan exhibits beneficial effects on both oxidative stress and inflammation, as well as beneficial effects on lipid metabolism and 
metabolic syndrome. These findings suggest that irbesartan might be more useful than other ARBs in high-risk patients with hypertension.

\section{CONFLICT OF INTEREST}

The authors declare no conflict of interest.

\section{ACKNOWLEDGEMENTS}

This study was supported in part by grants from Vehicle Racing Commemorative Foundation, Tokyo, Japan. We acknowledge the technical support services of Ken-ichi Inoue, $\mathrm{PhD}$ and Ryoichi Sohma, PhD, Research Support Center, Dokkyo Medical University, Mibu, Tochigi, Japan.

1 Siragy HM, Bedigian M. Mechanism of action of angiotensin-receptor blocking agent. Curr Hypertens Rep 1999; 1: 289-295.

2 Siragy HM. AT(1) and AT(2) receptors in the kidney: role in disease and treatment. Am J Kidney Dis 2000; 36(Suppl 1): S4-S9.

3 Weir MR, Dzau VJ. The rennin-angiotensin-aldosterone system: a specific target for hypertension management. Am J Hypertens 1999; 12: 205S-213S.

4 Schiffrin EL. Vascular and cardiac benefits of angiotensin receptor blockers. Am J Med 2002; 113: 409-418.

5 Schmieder RE. Mechanisms for the clinical benefits of angiotensin II receptor blockers. Am J Hypertens 2005; 18: 720-730.

6 Taguchi I, Inoue T, Kikuchi M, Toyoda S, Arikawa T, Abe S, Node K. Pleiotropic effects of angiotensin receptor blockers on dyslipidemia. Curr Vasc Pharmacol 2011; 9: 129-135.

7 Schpp M, Janke J, Clasen R, Unger T, Kintscher U. Angiotensin type 1 receptor blockers induce peroxisome proliferators-activated receptor-gamma activity. Circulation 2004; 109: 2054-2057.

8 Takai S, Jin D, Miyazaki M. Irbesartan prevents metabolic syndrome in rats via activation of peroxisome proliferator-activated receptor $\gamma$. J Pharmacol Sci 2011; 116: 309-315.

9 Kurtz T. New treatment strategies for patients with hypertension and insulin resistance. Am J Med 2006; 119: 24S-30S

10 Benson SC, Pershadsingh $\mathrm{HA}, \mathrm{Ho} \mathrm{Cl}$, Chittiboyina A, Desai P, Pravenec M, Qi N, Wang J, Avery MA, Kurtz TW. Identification of telmisartan as a unique angiotensin II receptor antagonist with selective PPAR $\gamma$-modulating activity. Hypertension 2004; 43 993-1002.

11 Chiarelli F, Di Marzio D, Santilli F, Mohn A, Blasetti A, Cipollone F, Mezzetti A, Verrotti A. Effects of irbesartan on intracellular antioxidant enzyme expression and activity in adolescents and young adults with early diabetic angiopathy. Diabetes Care 2005; 28 : 1690-1697.

12 Rifai N, Tracy RP, Ridker PM. Clinical efficacy of an automated high-sensitivity C-reactive protein assay. Clin Chem 1999; 45: 2136-2141.

13 Carson RT, Vignali DAA. Simultaneous quantification of 15 cytokines using a multiplex flow cytometric assay. J Immnunol Methods 1999; 227: 41-52.

14 de Jager W, te Velthuis H, Prakken BJ, Kuis W, Rijkers GT. Simultaneous detection of 15 human cytokines in a single sample of stimulated peripheral blood mononuclear cells. Clin Diagn Lab Immunol 2003; 10: 133-139.

15 Cearone MR, Belcalo G, Carratelli M, Cornelli U, De Sanctis MT, Incandela L, Barsott A, Terranova R, Nicolaides A. A simple test to monitor oxidative stress. Int Angiol 1999; 18: 127-130.

16 Cornelli U, Terranova R, Luca S, Cornelli S, Alberti A. Bioavailability and antioxidant activity of some food supplements in men and women using the D-Roms test as a marker of oxidative stress. J Nutr 2001; 131: 3208-3211.
17 Cavalleri A, Colombo C, Venturelli E, Miceli R, Mariani L, Cornelli U, Pala V, Berrino $F$, Secreto $G$. Evaluation of reactive oxygen metabolites in frozen serum samples. Effect of storage and repeated thawing. Int J Biol Markers 2004; 19 . 250-153.

18 Kehrer JP. The Haber-Weiss reaction and mechanisms of toxity. Toxicology 2000; 149 : 43-55.

19 Parving HH, Lehnert H, Brochner-Mortensen J, Gomis R, Andersen S, Arner P. The effect of irbesartan on the development of diabetic nephropathy in patients with type 2 diabetes. N Engl J Med 2001; 345: 870-878.

20 Lewis EJ, Hunsicker LG, Clarke WR, Beri T, Pohl MA, Lewis JB, Ritz E, Atkins RC, Rohde R, Raz ICollaborative Study Group. Renoprotective effect of the angiotensinreceptor antagonist irbesartan in patients with nephropathy due to type 2 diabetes. $N$ Engl J Med 2001; 345: 851-860.

21 Massie BM, Carson PE, McMurray JJ, Komajda M, McKelvie R, Zile MR, Anderson S, Donovan M, Iverson E, Staiger C, Ptaszynska AI-PRESERVE Investigators. Irbesartan in patients with heart failure and preserved ejection fraction. N Engl J Med 2008; 359: 2456-2457.

22 Yusuf S, Healy JS, Pogue J, Chrolavicus S, Flather M, Hart RG, Hohnloser SH, Joyner $\mathrm{CD}$, Pfeffer MA, Connolly SJ, ACTIVE I Investigators. Irbesartan in patients with atrial fibrillation. N Engl J Med 2011; 364: 928-938.

23 Lee C, Olson P, Evans RM. Minireview: lipid metabolism, metabolic disease, and peroxisome proliferator-activated receptors. Endocrinology 2003; 1446: 2201-2207.

24 Folli F, Saad MJ, Velloso L, Hansen H, Carandente O, Feener EP, Kahn CR. Crosstalk between insulin and angiotensin II signalling systems. Exp Clin Endocrinol Diabetes 1999; 107: 133-139.

25 Furuhashi M, Ura N, Higashiura K, Murakami H, Tanaka M, Moniwa N, Yoshida D, Shimamoto K. Blockade of the renin-angiotensin system increases adiponectin concentrations in patients with essential hypertension. Hypertension 2003; 42: 76-81.

26 Agata J, Nagahara D, Kinoshita S, Takagawa $Y$, Moniwa N, Yoshida D, Ura N, Shimamoto K. Angiotensin II receptor blocker prevents increased arterial stiffness in patients with essential hypertension. Circ J 2004; 68: 1194-1198.

27 Derosa G, Fogari E, D'Angelo A, Cicero AFG, Salvadeo SAT, Rogonesi PD, Ferrari I, Gravina A, Fassi R, Fogari R. Metabolic effects of telmisartan and irbesartan in type 2 diabetic patients with metabolic syndrome treated with rosiglitazone. J Clin Pharm Ther 2007; 32: 261-268.

28 Inoue T, Node K. Telmisartan as a metabolic sartan for targeting vascular failure. Expert Opin Pharmacother 2008; 9: 1397-1406.

29 Lehmann JM, Moore LB, Smith-Oliver TA, Wilkinson WO, Willson TM, Kliewer SA. An antidiabetic thiazolidinedione is a high affinity ligand for proxisome proliferatoractivated receptor (PPAR $\gamma$ ). J Biol Chem 1995; 270: 12953-12956.

30 Wakino S, Law RE, Hsuch WA. Vascular protective effects by activation of nuclear receptor PPAR- $\gamma$. J Diabetes Complications 2002; 16: 46-49.

31 Schiffrin EL, Amiri F, Benkirane K, Iglarz M, Diep QN. Peroxisome proliferatoractivated receptors: vascular and cardiac effects in hypertension. Hypertension 2003; 42: 664-668.

32 Campbell IW. The clinical significance of PPAR gamma agonism. Curr Mol Med 2005; 5: 349-363.

33 Dandona P, Dhindsa S, Ghanim H, Chaudhuri A. Angiotensin II and inflammation: the effect of angiotensin-converting enzyme inhibition and angiotensin II receptor blockade. J Hum Hypertens 2007; 21: 20-27.

34 Heinecke JW, Li W, Francis GA, Goldstein JA. Tyrosyl radical generated by myeloperoxidase catalyzes the oxidative cross-linking of proteins. J Clin Invest 1993; 91: 2866-2872.

35 Inoue T, Morooka T, Moroe K, Ikeda H, Node K. Effect of telmisartan on cholesterol levels in patients with hypertension-Saga Telmisartan Aggressive Research (STAR). Horm Metab Res 2007; 39: 1-5. 